\title{
Detecting and combating fake news on web 2.0 technology in the 2019 political season Indonesia
}

\author{
Samuel Anderson
}

Universitas Diponegoro, Semarang, Indonesia

Email: samuelanderson@student.undip.ac.id

Hapsari Dwiningtyas Sulistyani

Universitas Diponegoro, Semarang, Indonesia

Email: hapsarisulistyani@yahoo.com

\begin{abstract}
The digital age has come with lots of misinformation on the internet (web 2.0). The difference between real and fake news is unclear. This paper therefore scientifically employs algorithms and the evolution tree to help in the detection of fake news. Social bots in the spread of fake news are also detected by BotOrNot. The research employs an in-depth qualitative but informal interview with 102 participants who are internet and social media-active as well as prospective Indonesian electorates to investigate the spread and believe in fake news. The result indicates that about 91 of the informants experience the spread of fake news on daily basis, out of which 67 succumb to the truthfulness of the news. This article therefore develops a trend of battling fake news with the application of the Inoculation theory and citizen journalism as tools to eradicate fake news that may emerge before and during the 2019 election. 'Ohmynews' and 'ABC blogs' in the South Korean 2002 general elections and the Australian 2007 Federal elections respectively will be used as models of citizen journalism to deal
\end{abstract}


with fake news that may trend on the Web 2.0 (where social media application are enabled) in the 2019 Indonesian polls.

Keywords: Citizen Journalism, Inoculation Theory, Fake News, Detection, Elections

\section{Introduction}

Digital evolution has taken over the world now and it has come to stay. It is for this reason that many pieces of information that is not true could be made viral within a very short time. Keyes confirms that we live in a "post-truth" era where fake news is witnessed on a daily basis (Keyes, R, 2004). The Web 2.0 Technology as the enabler of fake news spread is referred to as the technological interactive and participative platform that allows the creation and sharing of information and for that matter, misinformation too on social network and media. It is on this web that all the social media networks are connected. That is, the global and easy access to Web 2.0 and its connected social applications which enables information sharing makes it so easy for anyone to post any kind of content on social media including fake news (Tambuscio, M.et.al, 2015).

Fake news is referred to as an array of misleading news style stories that are fabricated and promoted on social media to deceive the public for ideological and or financial gain (Alcott, H., and Gentzkow, M., 2017). Fake news has being on the rise especially before and during elections just like it happened in the 2016 general elections in the United States of America. Politicians use propaganda; where truth is twisted to suit their own whims and caprices to win votes. Others may intentionally create misinformation of a higher degree just to make money from the number of views they may have on social networks. Indonesia is no exception to this phenomenon. Fake news and hoaxes are common even in non- electioneering times. This raises the fear that the general populace may be bound to believe crafted false pieces of information intended to deceive them. In view of this, fake news may to a large extent pose dangers and threats to Indonesia if people are made to believe false information that are chaos-related in an electioneering-tensed atmosphere.

Fake news and hoaxes spread everyday on social media. In Indonesia it is so common to experience fake news since the late 2016's. The Strait Times, (2018) reports that, "incumbent governor Basuki Tjahaja Purnama, Jakarta's first Christian and ethnically Chinese leader was lambasted by Islamic hardliners after an edited video appeared to show him insulting the Quran." 
This fake news was produced and made viral by The Muslim Cyber Army and the allegations captured in the content caused hundreds of thousands of conservative Muslims to protest on the streets of Jakarta against the then Governor. Even though he was an ally to the sitting president, Joko Widodo, he was jailed for blasphemy after losing the election to a Muslim contender.

If fake news could make people react massively this way, then fake news that may go viral in the 2019 electioneering period may pose danger and threat to the peace and unity of the country.

Even though fake news that circulated during the 2014 national election in Indonesia that "Mr. Joko Widodo (who was a candidate for the Partai Demokrat Indonesia) is a Catholic and not a Muslim" did not have any huge impact over that year's election. The trend of believing in fake news has changed in recent years just like the survey proves that many are those who turn to believe fake news these days (Alcott, H., and Gentzkow, M., 2017).

The rise of fake news in recent times in Indonesia is so alarming to the extent that authorities have to intervene. This has even gone to the extent that the president had to caution his populace on it in almost all his recent speeches and public addresses. The news agency Kabar24 on the sixth of June, 2018 reports the president's caution against fake news; "...let us together stop the spread of false news or incitement containing slander and hatred on social media."

A legal practitioner by name Todung Mulya Lubis also shares his sincere concern on the alarming situation. He suggests that the laws on freedom of public opinion; "Law 9/1998 and Law No. 11/2008 on ITE" must be entrenched, reinforced and strictly followed (Pérez-Rosas Verónica et. al, 2017)

Also, Alisa Wahid, the coordinator for the Gusdorian Indonesia Network affirms the fact that fake news or false claims prop up before and during elections but this time round, it is getting uncontrollable (Pérez- Rosas Verónica, et.al, 2017)

A survey conducted by the Indonesia Internet Service Providers Association, (2017) indicates that 97.7percent of the internet users in the country rely basically on social media for information. The information system on the internet today is characterized by inaccurate spread of information (Van der Linden, S et.al 2017).

Although scientific interventions like the algorithm and evolution tree in terms of fake news detection are good approaches but the process takes time 
and before its detection, the spread may have already caused mayhem (Gupta, A., et.al 2017)

This therefore raises the concern to have an advocacy on checking the truthfulness of information especially during electioneering periods where politicians try to win votes by using propaganda against their opponents. Citizen journalism as a tool for this advocacy can contribute in checking on political false claims as Indonesia goes to the polls in 2019.

\section{Aim of the Study}

This research is basically to examine the growing spread of fake news in Indonesia in recent times, scientific detection of fake news and its eradication, as well as to find out to what extent internet consumers experience fake news on daily basis. The research yearns to know the percentage of those who may believe in the fake news they experienced. Then finally, propose a possible solution to the battling of fake news.

\section{Methods}

This paper uses the qualitative approach of in-depth interview to find out if potential Indonesian electorates are indeed experiencing the spread of fake news on a daily-basis and also if they believe in it.

Over a period of seven months, 102 potential electorates who are also active social media users with origins of Aceh, Sumatera Utara, Sumatera Barat, Riau, Kepulauan Riau, Jambi, Bengkulu, Sumatera Selatan, Kepulauan Bangka Belitung, Lampung, Banten, Jawa Barat, Jakarta, Jawa Tengah, Yogyakarta, Jawa Timur, Bali, Nusa Tenggara Barat, Nusa Tenggara Timur, Kalimantan Barat, Kalimantan Selatan, Kalimantan Tengah, Kalimantan Timur, Kalimantan Utara, Gorontalo, Sulawesi Selatan, Sulawesi Tenggara, Sulawesi Tengah, Sulawesi Utara, Sulawesi Barat, Maluku, Maluku Utara, Papua, Papua Barat provinces were engaged in separate informal interviews. Averagely, each of these provinces was represented by at least three informants. The ages of these informants ranged from 18 to about 52 years averagely.

\section{Theorization (Inoculation)}

The Inoculation theory was propounded by McGuire to preventively resist misinformation as analogous to immunizations and vaccines in the 
medical field in prevention of future diseases (Compton J. et. al 2013; Banas J, and Rains S., 2010).

Inoculation comes with two core elements in its process viz; affective and cognitive often referred to as "threat" and "refutational preemption". The role of perceived risk or "threat" is largely motivational and refers to the recognition that one's attitude on an issue is vulnerable to attack, whereas "refutational preemption" is concerned with providing people with concise arguments to assist in resisting persuasion attempts (Compton J., 2013; Compton J. et. al 2016)

Van confirms that the theory in its application have proved effective in many cases of fighting fake news (Van der Linden, S, 2017; Van der Linden, S, 2017a). With that regard, in the case of Indonesia's 2019 political season, it will be prudent to forewarn the general populace (as a 'refutational preemption') on the spread of fake news (which has evolved as a 'threat') to prevent its adverse consequences as Compton posits that an explicit forewarning against misinformation has being proved by many researchers as one of the most effective ways (Compton J., 2013).

Applicably, the warnings by various Indonesian authorities and even the president against fake news as stated in the introduction section is in the right direction and must be boosted.

\section{Fake News Detection (scientific)}

Scientifically, several algorithms have been created to effectively detect fake news and hoaxes. The algorithms are generally categorized into three which are; feature- based, graph-based and propagation- modelling.

Feature-based algorithms leverage the distinct characteristics for detection by using them as features in a machine-learning-model or rule-based framework (Horne, B. D, and Sibel, A., 2017).

Graph-based algorithms are developed to identify dense-blocks or dense subgraphs of users and information in a network on Web 2.0 (Leman, A, et.al, 2010)

Propagation-modelling algorithms create information spread models for true information and use these models to identify false information (Horne, B. D, and Sibel, A., 2017).

Naturally, the accuracy of these algorithms depends on the task and 
datasets that is used. However, a lot of the algorithms reach the high eighties and nineties proving their effectiveness on large-scale real-world datasets of fake news and hoaxes, see Fig.1.

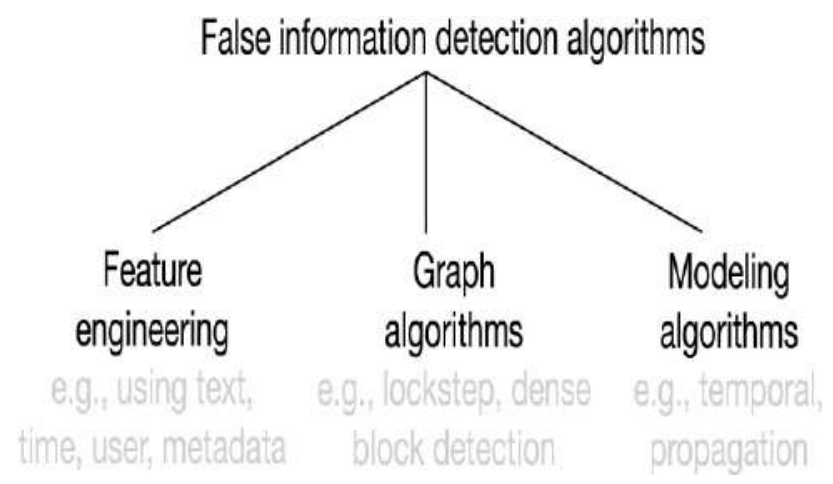

Figure 1; Algorithm for detection, (Srijan Kumar and Neil Shah, 2018)

Attention is given to the feature engineering or text-based detection because text-analysis is core to the identification of misinformation and the content of fake news is primarily in the form of text. Similarly to opinionbased textual detection methods, scholars with research works in this category are often feature-based, where features can broadly be categorized as either stylometric (number of characters in a word), complexity- oriented (readability indices) or psycholinguistic (Pennebaker, J.W., et.al, 2001)

An epitome of the use of the text based detection as an effective tool is a research conducted by Vahed et al which identified fake news on Twitter using the text based detection (Vahed, Q. et.al, 2011). They collected manual annotations for over 10,000 tweets and developed three categories of features to identify the false tweets which is based on content (unigram, bigrams and partof-speech), but also used user information. (whether user has previously posted false information) and Twitter-specific information (hashtags and URLs).

These features were converted into their log-likelihood ratio of being from the true or false class based on their distribution in the training data and the combined score was used for classification. This model achieved a mean average precision score of $95 \%$, indicating near-perfect classification. Individually, content features performed the best, followed by network feature and lastly hashtag and URL based Twitter features. Content based features also proved one of the best performing features in the scholarly works of Meng et al, which also focused on fake tweet detection (Jiang, M., 2014). 
This scientific detection could be employed and replicated on any of the applications associated with the Web 2.0 by the stakeholders responsible for the technological aspect of misinformation spread in Indonesia to get to know which pieces of information are false in crucial tensed moments of the political 2019 season.

\section{Bots in the Spread of Fake news}

There have being several scientific and technological ways that enables and speeds up the spread of fake news one of which is the social bot. Social bots imply a Chat robot used mostly on social media networks to automatically generate and spread messages with fake accounts, followers inter alia.

A detection program, Bot Or Not is normally used to detect social bots as it has been tested on a large amount of data with prove of generating reliable results for simple to medium and sophisticated social bots [26]. BotOrNot offers a public API endpoint which was accessed using Python. The detection program generates a score ranging from $0-1$ with a higher score indicating stronger social bot-like behavior. Social media accounts regarded as social bots must at least be scored at 0.7 (Detiknews, "Saya Joko Widodo", Hentikan Penyebaran Berita Bohong, 08 June 2017).

Tambuscio also provide a useful framework for determining whether a piece of information was posted by human or social bot using the python API [18]. A username is fed into Python API (https://github.com/truthy/botornotpython), the framework analyzes the user's profile, spanning content and other metadata and returns a score that suggests the likelihood that the suspected account is a bot or not.

In the detection process, a second check is executed by analyzing six features that proves to be useful in detecting social bots. That is, verified accounts, information- sharing frequency, follower-to-followed ratio, account language, account creation time and profile picture (Jiang, M., et.al, 2014). If an account is realized to display social bot-like behavior, the account is scored 1 . If it does not, it scores 0 . A summation of the feature score ranges from 0 to 6 for each account. A higher score indicates a higher probability of the account being a social bot. Accounts with a score of at least 5 are classified as social bots. To make sure that the classification is successful, two manual checks are often conducted by two coders each. The first manual check relates to the accounts that were classified as social bots in step I and II of fig.2. The goal here is to 
judge if the accounts were correctly classified as social bots.

The criteria for the manual checks often include; Was the content of information original, intelligent and human-like? Does the information have irony, sarcasm or jokes? Were there any references to friends, family members inter alia? Is the profile details individualized? Does the account follow suspicious accounts? Did the account have suspicious followers? (Bessi, Alessandro and Ferrara Emilio, 2016).

\section{Distinction between Real and Fake News}

The differences between fake news and real news can be investigated using the evolution tree characteristics viz; breadth, depth and degree. The breadth represents the width while depth represents the height of the evolution tree. Based on the evolution tree adjusted by content-level similarity and timestamping, breadth and depth is derived by traversing the entire tree and recording the number of nodes in the level having the largest number of nodes as the breadth and also, by recording the length of the longest path from the root to any terminal node as depth. The relevance of breadth is that an evolution tree with larger breadth indicates that the non-altered news content spreads out more widely. In the case of an evolution tree with larger breadth, it is more likely that other users just spread exactly the same content. Contrarily, the relevance of depth is that a tree with larger depth indicates that news content is subjected to more alterations during its spread.

The $t$-test results for this phenomena indicates that the average breadth of fake news $(M=5.95, S D=1.79)$ is smaller than that of real news $(M=7.83$, $\mathrm{SD}=4.12, \mathrm{t}=-2.48, \mathrm{p}<.05)$. On the other hand, the average depth of fake news $(\mathrm{M}=2.07, \mathrm{SD}=0.76, \mathrm{t}=2.46, \mathrm{p}<.05)$ is greater than that of real news $(M=1.67, S D=0.56)$. It is therefore clear that fake news undergo a myriad of modifications by many users over the spreading process. This also means that the content was not modified uniformly at the same time giving different twists to the same circulating piece of news.

Adversely, real stories showed a good range of breadth but smaller vertical depth, indicating that the news story spread concurrently without any modification of the content.

In a sum, real news items are typically broadcast rapidly and widely by a great number of news outlets and social media users share the stories without altering much of the original content. But with fake news stories, social media 
users tend to modify the original content at their discretion. This may be partly due to users having some doubt of the reliability of the source and or the content itself.

\section{Citizen Journalism as a Tool}

Citizen journalism implies the changes in the global news and journalism landscape in which ordinary people who are not associated with the traditional news institutions and journalism professions, create, collect, comment on and disseminate news and journalism (Gillmor, D., 2004).

Notwithstanding Atton (2009) sees citizen journalism as

"a philosophy of journalism and a set of practices that are embedded within the everyday lives of citizens, and media content that is both driven and produced by those people... (and whose) practices emphasize first person, eyewitness accounts by participants"

Atton's view places much emphasis on both the agency and autonomy of individual citizens in their desire to capture and share personal experiences of things they perceive to be in the public interest with fellow citizens without necessarily following prescribed journalistic rules or making economic gains from their endeavours.

In a politically charged atmosphere, the news need to be told as it is right from the grass root. Thus, citizens who find themselves present in a particular happening or issue, assume the role of a journalist to report the incidence (Fang, J., et.al, 2013). Atton and Hamilton observe the role of citizen journalism reports as a corrective and a check on the mainstream news and social media especially at times when the quality and truthfulness of coverage has been compromised (Atton, C. and Hamilton, J.F., 2015).

A big example of a proved and effective citizen journalism that fought against all odds of irrelevant and untrue news in a political season is that of the OhmyNews in the South Korean 2002 elections.

OhmyNews is an online news site and media agency that was created to give opportunity to the general populace to voice out valid concerns which had no place in the mainstream media environment.

OhmyNews had only 8.3 percent professional reporters. The rest of their reporters came from groups that would not previously have had a voice through the media. About 20,000 citizen journalists made contribution to the news. 
A 2004 survey indicates that 14.6 percent of its reporters were office workers, 3.5 percent were teachers while 0.2 percent were lawyers. The rest came from various parts of the citizenry.

The operations of the OhmyNews rose to prominence due to the update of credible and accurate news they provided during the 2002 electioneering year. OhmyNews was in the center of this online deliberation news and updated their coverage of election-related events every thirty minutes.

Thus, news from both professional and citizen journalists are wellchecked and edited from the source before its release. This practice gave no room for fake news to take over the internet and or the other media because the general public has found integrity and trust with OhmyNews.

In relation to the up-coming 2019 elections in Indonesia, this media form of convergence could possibly be followed as a model to battle fake news (Bruns, A., 2008).

Another epitome that could be modelled after is the ABC blogs. The $\mathrm{ABC}$ blogs quiet similar to that of OhmyNews, is a conglomerate of community based sites which acted as a watchdog to the mainstream and online media in Australia and even beyond during the 2007 elections.

The citizen journalists here, observe and analyze virtually every piece of information that passes through the publication gates of the journalism industry and other 'official' sources. Interesting and relevant news for various communities are therefore given prior attention for publication. Natives of various communities were encouraged to submit reports on happenings of community-interest that they have witnessed. These pieces of information were therefore critically checked in accordance to its source and critically examined with other background information to make it authentic. Accuracy and the bias level of the news are also tested then finally the news is debated on from various viewpoints of professional journalists and edited before the online publication is made (Bruns, A., 2008).

The provision of the news from a credible and non-politically biased source of this nature give no room to the rise of fake news since the general populace have a trusted source of news supply regarding their news of interest [22]. This makes it a good model for Indonesia to follow suit in the 2019 political season to combat fake news. 


\section{Findings}

Out of 102 participants, 81 of them which is representative of $82.6 \%$ revealed how they experienced fake news virtually every day. The percentage of the participants who believed in the fake news and for that reason often shared it amounts to about 68.3 which is about 67 of the participants.

\section{Discussion}

Since the emergence and viral spread of fake news eruption, there have being many efforts to fight it, ranging from scientific detections, and governmental policies to technological adjustments, censorship and counterarguments.

Facebook as one of the social media giants that avails the affordance of spreading fake news have in recent years tried to guide its users in identifying fake news. Facebook launched that campaign last year in about 14 countries where its users who clicked on Facebook's ad will be redirected to its help centre, where they will see a list of 10 tips for identifying false stories. Meanwhile, a social media pundit, Felle, (2017) in an interview with the BBC's Daniel Thomas insists that until Facebook stops rewarding the architects of fake news with huge traffic, the problem of fake news getting viral will get aggravated instead (Daniels Thomas, 2017).

Policy-wise, there have being a lot of restrictions in many countries to stop the spread of fake news. Policy and lawmakers have also tried their best to combat the menace in a legal way just like the Indonesian lawmaker, Todung Mulya Lubis calls for the freedom of public opinion; "Law 9/1998 and Law No. $11 / 2008$ on ITE" to be revisited to fight the spread of fake news.

Many opinion leaders have even added their voice. One of them is the president of Indonesia, President Joko Widodo. He warns;

"we should only trust and talk to the mainstream media, newspapers, magazines, television because social media has got a lot of individuals delivering incorrect news because it is easy for anyone to create blogs, sites, tweets, Facebook contents and vlogs." (Pérez-Rosas Verónica, et.al., 2017)

Nevertheless, we still experience the spread of fake news in rather a fast-growing pace. The researcher argues that, even some of the mainstream media outlets out of bias, negligence and or ill-checked news may misinform its audience. 
The president, further said,

"it takes a joint effort to overcome the negative impact of the use of social media in a responsible way. One of them is to fight the spread of fake news and hoaxes through clarification and convey the right thing to the community." (Pérez-Rosas Verónica, et.al., 2017)

\section{Conclusion}

In accordance with the OhmyNews and the $\mathrm{ABC}$ blog examples, this paper with full accord, proposes citizen journalism as one of the best ways to battle against or inoculate digital citizens against fake news since it has being proven as effective in both cases of OhmyNews in South Korea and the ABC blog in Australia vis a-vis many other researches.

The media and other stakeholders are therefore admonished to follow this path to immune the general populace against fake news and its adverse effects during the 2019 electoral polls in Indonesia.

\section{References}

Akoglu, L., McGlohon, M., \& Faloutsos, C. (2010, June). Oddball: Spotting anomalies in weighted graphs. In Pacific-Asia Conference on Knowledge Discovery and Data Mining (pp. 410-421). Springer, Berlin, Heidelberg.

Allcott, H., \& Gentzkow, M. (2017). Social media and fake news in the 2016 election. Journal of economic perspectives, 31(2), 211-36.

Atton, C. \& Hamilton, J.F. (2015) Alternative journalism, London: Sage Publications.

Atton, C. (2009). Why alternative journalism matters. Journalism, 10(3), 283 285.

Banas, J. A., \& Rains, S. A. (2010). A meta-analysis of research on inoculation theory. Communication Monographs, 77(3), 281-311.

Bessi, A., \& Ferrara, E. (2016). Social bots distort the 2016 US Presidential election online discussion. First Monday, 21(11-7).

Bruns, A. (2008). Blogs, Wikipedia, Second Life, and beyond: From production to produsage (Vol. 45). Peter Lang.

Compton, J., Jackson, B., \& Dimmock, J. A. (2016). Persuading others to avoid 
persuasion: Inoculation theory and resistant health attitudes. Frontiers in psychology, 7, 122.

Detiknews, "Saya Joko Widodo", Hentikan Penyebaran Berita Bohong (2017, June 08.

Ferrara, E., Varol, O., Davis, C., Menczer, F., \& Flammini, A. (2016). The rise of social bots. Communications of the ACM, 59(7), 96-104.

Gillmor, D. (2006). We the media: Grassroots journalism by the people, for the people. “O’Reilly Media, Inc.”.

Gupta, A., Lamba, H., Kumaraguru, P., \& Joshi, A. (2013, May). Faking sandy: characterizing and identifying fake images on twitter during hurricane sandy. In Proceedings of the 22nd international conference on World Wide Web (pp. 729-736).

Horne, B. D., \& Adali, S. (2017). This just in: Fake news packs a lot in title, uses simpler, repetitive content in text body, more similar to satire than real news. arXiv preprint ar Xiv:1703.09398.

Jiang, M., Cui, P., Beutel, A., Faloutsos, C., \& Yang, S. (2014, May). Inferring strange behavior from connectivity pattern in social networks. In PacificAsia Conference on Knowledge Discovery and Data Mining (pp. 126-138). Springer, Cham.

Jiang, M., Cui, P., Beutel, A., Faloutsos, C., \& Yang, S. (2014, May). Inferring strange behavior from connectivity pattern in social networks. In PacificAsia Conference on Knowledge Discovery and Data Mining (pp. 126-138). Springer, Cham.

Jin, F., Dougherty, E., Saraf, P., Cao, Y., \& Ramakrishnan, N. (2013, August). Epidemiological modeling of news and rumors on twitter. In Proceedings of the 7th workshop on social network mining and analysis (pp. 1-9).

Keyes, R. (2004). The post-truth era: Dishonesty and deception in contemporary life. Macmillan.

Leiserowitz, A., Rosenthal, S., \& Maibach, E. (2017). Inoculating the Public against Misinformation about Climate Change. Global Challenges, 1(2). https://doi.org/10.1002/gch 2.201600008.

Pennebaker, J. W., Francis, M. E., \& Booth, R. J. (2001). Linguistic inquiry and word count: LIWC 2001. Mahway: Lawrence Erlbaum Associates, 71(2001), 2001.

Pérez-Rosas, V., Kleinberg, B., Lefevre, A., \& Mihalcea, R. (2017). Automatic 
detection of fake news. arXiv preprint arXiv:1708.07104.

Qazvinian, V., Rosengren, E., Radev, D., \& Mei, Q. (2011, July). Rumor has it: Identifying misinformation in microblogs. In Proceedings of the 2011 Conference on Empirical Methods in Natural Language Processing (pp. 15891599).

Shen, L., \& Bigsby, E. (2012). The SAGE handbook of persuasion developments in theory and practice.

Tambuscio, M., Ruffo, G., Flammini, A., \& Menczer, F. (2015, May). Factchecking effect on viral hoaxes: A model of misinformation spread in social networks. In Proceedings of the 24th international conference on World Wide Web (pp. 977-982).

Van der Linden, S., Leiserowitz, A., Rosenthal, S., \& Maibach, E. (2017). Inoculating the public against misinformation about climate change. Global Challenges, 1(2), 1600008.

Van der Linden, S., Leiserowitz, A., Rosenthal, S., \& Maibach, E. (2017). Inoculating the public against misinformation about climate change. Global Challenges, 1(2), 1600008. 